\title{
Intraoperative Peritoneal Lavage: Limitations of Current Evidence for Clinical Implementation
}

\author{
Duck-Woo Kim \\ Department of Surgery, Seoul National University Bundang Hospital, Seongnam, Korea
}

\section{See Article on Page 266-273}

Peritoneal recurrence after a curative resection of colorectal cancer is less common than lymphatic spread or hematogenous metastasis [1]. Moreover, peritoneal carcinomatosis often develops at a later stage of recurrent disease and is regarded as noncurable. Therefore, being able to predict the possibility of peritoneal recurrence at an early time after the original diagnosis and to prevent its occurrence would be a great advance in treating colorectal cancer [2].

Positive peritoneal lavage is a well-known risk factor for local/ peritoneal recurrence in patients with colorectal cancer and various other types of cancers. Among gastrointestinal malignancies, the significance of peritoneal cytology has been extensively studied in gastric cancer. The existence of free cancer cells at intraoperative peritoneal lavage has been reported to be one of the most accurate prognostic factors for gastric cancer and is now classified as Stage IV [3, 4]. Besides gastric cancer, the examination of peritoneal free cancer cell is an important staging step in pancreatic, ovarian and endometrial cancer [5]

Although positive peritoneal lavage is an established poor prognostic factor in colorectal cancer that has been proven in many studies, including several systemic reviews and meta-analyses [3, $6,7]$, examining the peritoneal cytology is still not a standard procedure for staging colorectal cancer. To be a reliable clinical indicator, future studies have to overcome several issues involving peritoneal lavage. The first is the differences in the methods of lavage and free cell detection. Proper timing of lavage is controversial. Some studies performed lavage immediately after the opening of

Correspondence to: Duck-Woo Kim, M.D.

Department of Surgery, Seoul National University Bundang Hospital, 82 Gumi-ro 173beon-gil, Bundang-gu, Seongnam 463-707, Korea

Tel: +82-31-787-7101, Fax: +82-31-787-4078

E-mail:kdw@snubh.org

(c) 2014 The Korean Society of Coloproctology

This is an open-access article distributed under the terms of the Creative Commons Attribution NonCommercial License (http://creativecommons.org/licenses/by-nc/3.0) which permits unrestricted noncommercial use, distribution, and reproduction in any medium, provided the original work is properly cited. the abdominal wall and some so did after the tumor resection [7]. Most of these studies used a $0.9 \% \mathrm{NaCl}$ solution as the lavage fluid, but the volume and the temperature of the solution were different from study to study. Most importantly, the methods for detecting free cancer cells varied and included conventional cytology, quantitative methylation specific polymerase chain reaction (PCR), immunological, immunobead quantitative PCR, radioimmunoassay or immunoperoxidase assay [8-12] methods. The staining technique was also different among the previous studies. These differences among the studies might result in a very wide range of positive peritoneal lavage ranging from $2.1 \%$ to $52 \%$, and this wide range makes selecting a high-risk group for local/peritoneal recurrence based on peritoneal lavage difficult. Secondly, a well-designed comparative study is insufficient for recommending positive peritoneal cytology as a clinical indicator on which practical decisions can be based. A recent prospective study showed an improvement in peritoneal recurrence and overall survival in patients with positive lavage who underwent intraperitoneal chemotherapy with mitomycin $\mathrm{C}$ compared to those who did not $[1,13]$.

Because positive peritoneal lavage is associated with a worse prognosis, a potential benefit of peritoneal lavage may exist for the identification of patients to receive adjuvant treatment. Further studies are needed to examine whether adjuvant treatment can improve the oncologic results of patients with positive peritoneal lavage.

\section{REFERENCES}

1. Noura S, Ohue M, Shingai T, Kano S, Ohigashi H, Yano M, et al. Effects of intraperitoneal chemotherapy with mitomycin $\mathrm{C}$ on the prevention of peritoneal recurrence in colorectal cancer patients with positive peritoneal lavage cytology findings. Ann Surg Oncol 2011;18:396-404.

2. Nishikawa T, Sunami E, Tanaka T, Tanaka J, Kiyomatsu T, Kawai K, et al. Incidence and prognostic significance of positive peritoneal lavage in colorectal cancer. Surg Today 2014 Nov 7 [Epub]. http:// dx.doi.org/10.1007/s00595-014-1066-2.

3. Kobayashi H, Kotake K, Sugihara K. Prognostic significance of 
peritoneal lavage cytology in patients with colorectal cancer. Int J Clin Oncol 2013;18:411-7.

4. Bae SJ, Shin US, Ki YJ, Cho SS, Moon SM, Park SH. Role of peritoneal lavage cytology and prediction of prognosis and peritoneal recurrence after curative surgery for colorectal cancer. Ann Coloproctol 2014;30:266-73.

5. Kasamatsu T, Onda T, Sasajima Y, Kato T, Ikeda S, Ishikawa M, et al. Prognostic significance of positive peritoneal cytology in adenocarcinoma of the uterine cervix. Gynecol Oncol 2009;115:488-92.

6. Bosanquet DC, Harris DA, Evans MD, Beynon J. Systematic review and meta-analysis of intraoperative peritoneal lavage for colorectal cancer staging. Br J Surg 2013;100:853-62.

7. Mohan HM, O'Connor DB, O'Riordan JM, Winter DC. Prognostic significance of detection of microscopic peritoneal disease in colorectal cancer: a systematic review. Surg Oncol 2013;22:e1-6.

8. Vogel I, Kalthoff H. Disseminated tumour cells: their detection and significance for prognosis of gastrointestinal and pancreatic carcinomas. Virchows Arch 2001;439:109-17.
9. Kamiyama H, Noda H, Takata O, Suzuki K, Kawamura Y, Konishi F. Promoter hypermethylation of tumor-related genes in peritoneal lavage and the prognosis of patients with colorectal cancer. J Surg Oncol 2009;100:69-74.

10. Bosch B, Guller U, Schnider A, Maurer R, Harder F, Metzger U, et al. Perioperative detection of disseminated tumour cells is an independent prognostic factor in patients with colorectal cancer. $\mathrm{Br}$ J Surg 2003;90:882-8.

11. Temesi R, Sikorszki L, Bezsilla J, Botos A, Kovacs J, Tihanyi T. Impact of positive intraabdominal lavage cytology on the long-term prognosis of colorectal cancer patients. World J Surg 2012;36: 2714-21.

12. Rossi Del Monte S, Ranieri D, Mazzetta F, Kazemi Nava A, Raffa S, Torrisi MR, et al. Free peritoneal tumor cells detection in gastric and colorectal cancer patients. J Surg Oncol 2012;106:17-23.

13. Hompes D, Tiek J, Wolthuis A, Fieuws S, Penninckx F, Van Cutsem E, et al. HIPEC in T4a colon cancer: a defendable treatment to improve oncologic outcome? Ann Oncol 2012;23:3123-9. 